\title{
Environmental Risk Assessment of Enterprises from Key Industries in Tianjin Binhai New District
}

\author{
Long Zhou ${ }^{1, a}$, Hao Zhou ${ }^{2, b}$ and Liyong Fan ${ }^{3, c}$ \\ ${ }^{1}$ School of Management, Tianjin University of Technology, Tianjin 300384, China \\ ${ }^{2}$ Environmental Science \& Safety Engineering College, Tianjin University of Technology, Tianjin \\ 300384, China \\ ${ }^{3}$ Longjitaihe Industrial Co., Ltd., Baoding 074000, China

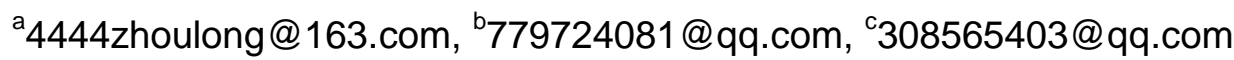

Keywords: Environmental risk of enterprises, Binhai New District, assessment.

\begin{abstract}
This paper aims to comprehensive research methods both in China and abroad and develop a practical method of environmental risk assessment about enterprises from key industries based on the data of Tianjin Binhai New District. This method consider the following factors: types of industries, the enterprise production scale, emergency preparedness and protective measures, the distance between enterprises and environmental protection target, and use Delphi method to collect data in order to guarantee the accuracy.
\end{abstract}

\section{Introduction}

With the continuous development of regional economy in China, The coordinated development of beijing-tianjin-hebei has risen as a national strategy. Recently, the Tianjin free trade zone was founded in Tianjin Binhai New District. There will be a new development in Tianjin Binhai New District. So Environmental pollution and environmental risks will follow. A more realistic and accurate method of environmental risk assessment is necessary in order to forecast the environmental risk of enterprises in Binhai New District [1]. This paper considers two aspects of the probabilities of environmental emergencies and the consequences of environmental accidents to form a new method of environmental risk assessment based on the data of enterprises from key industries in Tianjin Binhai New District.

\section{Methods of environmental risk assessment of enterprises}

Due to the characteristics of industry, some enterprises are more likely to have emergency than other companies, so the environmental risk of those enterprises is higher. Due to close to the water source or residential areas, when some sudden environmental incidents occur in some enterprises, the environmental impact is even greater, so the environmental risk of those enterprises is also higher [2]. In summary, environmental risk of enterprises consider two aspects of the probabilities of environmental emergencies and the consequences of environmental accidents.

We use value of risk (R) express enterprise environmental risk, defined as the product of factor $\mathrm{P}$ which is the probability of enterprise accident and factor $C$ which is the environmental consequences caused by accidents, so $\mathrm{R}=\mathrm{P} \times \mathrm{C}$. It is generally believed the accident probability of enterprises (P) is related to the types of industries $(\mathrm{L})$. And the consequences of environmental accidents $(\mathrm{C})$ is related to the enterprise production scale (A), emergency preparedness and protective measures (K), the distance between enterprises and environmental protection targets $(G)$ [3].

Therefore, the accident probability of enterprises can be defined as a formula: $\mathrm{P}=\mathrm{L}$

The consequences of environmental accidents (C) is defined as the following formula: $C=A \times K \times G$

While the environmental risk value of enterprises $R=P \times C$, so $R=L \times A \times K \times G$. 


\subsection{The factor calculation of different types of enterprises ( $L$ ).}

The paper is based on classification of enterprises from key industries in Binhai New District, and makes the expert consultation questionnaire about Delphi, then choose 10 to 15 experts from different industries to score the related content. Finally get key industries of Binhai New District environmental risk weights [4], the results shown in the following table:

Table 1 Environmental risk weights of enterprises from key industries in Binhai New District

\begin{tabular}{|c|c|c|}
\hline \multirow{2}{*}{$\begin{array}{c}\text { Oil processing and } \\
\text { coking industry }\end{array}$} & The manufacture of refined oil products & 88 \\
\cline { 2 - 3 } & Coking & 85 \\
\cline { 2 - 3 } & The manufacture of basic chemical raw materials & 87 \\
\cline { 2 - 3 } $\begin{array}{c}\text { Chemical raw } \\
\text { materials and chemical } \\
\text { manufacturing } \\
\text { industry }\end{array}$ & Fertilizer manufacturing & 60 \\
\cline { 2 - 3 } \begin{tabular}{c} 
Pesticide manufacturing \\
\cline { 2 - 3 }
\end{tabular} & The manufacture of coatings, printing ink, pigment and similar & 88 \\
\cline { 2 - 3 } & products & 85 \\
\hline $\begin{array}{c}\text { Pharmaceutical } \\
\text { manufacturing } \\
\text { industry }\end{array}$ & Special chemical products manufacturing & 85 \\
\cline { 2 - 3 } & Chemical and pharmaceutical raw materials manufacturing & 67 \\
\hline
\end{tabular}

Note: 60-70 points: environmental risk is in general; 70-80 points: environmental risk is larger; 80-90 points: environmental risk is big; $90-100$ points: environmental risk is very large.

\subsection{The factor calculation of enterprise production scale (A).}

Due to differences in enterprise production scale, potential environmental risks for each enterprise are different. The larger the enterprise production scale gets, the greater the potential environmental risk get. So put the specific enterprise production scale $(\mathrm{m})$ compare with their industry total production scale (n), we can get enterprise production scale factor (A) [5]. The specific formula is defined as follows:

$$
\mathrm{A}=\frac{m}{n}
$$

\subsection{The factor calculation of emergency preparedness and protective measures (K).}

The factor of emergency preparedness and protective measures refers to the environmental emergency plans of enterprises, emergency training, and emergency drill and so on. The factor value is the product of the environmental risk value and weight of each index [6]. The specific evaluation index and score shown in the following table:

Table 2 The evaluation index system of enterprises' emergency preparedness and protective measures

\begin{tabular}{|c|c|c|c|c|}
\hline \multirow{4}{*}{ The target layer } & The index layer & $\begin{array}{c}\text { High risk } \\
\text { (3 points) }\end{array}$ & $\begin{array}{c}\text { Medium risk } \\
\text { (2 points) }\end{array}$ & $\begin{array}{c}\text { Low risk } \\
\text { (1 point) }\end{array}$ \\
\cline { 3 - 5 } & $\begin{array}{c}\text { Environmental emergency } \\
\text { plans of enterprises }\end{array}$ & No & Yes & Yes \\
\cline { 2 - 5 } $\begin{array}{c}\text { The factor of } \\
\text { enterprises' } \\
\text { emergency } \\
\text { preparedness and } \\
\text { protective measures }\end{array}$ & Emergency training & No & No & Yes \\
\cline { 2 - 5 } & Emergency drill & No & No & Yes \\
\cline { 2 - 5 } & Emency handling & No & No & Yes \\
\cline { 2 - 5 } & Emergency material & No & Yes & Yes \\
\hline
\end{tabular}


Invite experts from all industries to score the content that the evaluation index of enterprises' emergency preparedness and protective measures [7]. The weight of each index shown in the following table:

Table 3 The weight of the evaluation index of enterprises' emergency preparedness and protective measures

\begin{tabular}{|c|c|c|}
\hline The target layer & The index layer & The weight \\
\hline \multirow{4}{*}{$\begin{array}{c}\text { The factor of enterprises' } \\
\text { emergency preparedness and } \\
\text { protective measures }\end{array}$} & $\begin{array}{c}\text { Environmental emergency plans of } \\
\text { enterprises }\end{array}$ & 0.31 \\
\cline { 2 - 3 } & Emergency training & 0.12 \\
\cline { 2 - 3 } & Emergency drill & 0.24 \\
\cline { 2 - 3 } & Emergency handling equipment & 0.22 \\
\cline { 2 - 3 } & Emergency material reserves & 0.11 \\
\hline
\end{tabular}

\subsection{The factor calculation of the distance between enterprises and environmental protection targets (G).}

The study selected drinking water sources, the common water, protected areas, hospitals and schools as environmental protection targets [8]. The method about the factor calculation of the distance between enterprises and environmental protection targets as follows:

Table 4 The method about the factor calculation of the distance between enterprises anenvironmental protection targets

\begin{tabular}{|c|c|c|c|c|}
\hline \multirow{2}{*}{ The environmental protection target } & \multicolumn{3}{|c|}{ The value of distance factor } \\
\cline { 2 - 5 } & $\begin{array}{c}100 \\
\text { meters }\end{array}$ & 500 meters & $\begin{array}{c}1000 \\
\text { meters }\end{array}$ & $\begin{array}{c}5000 \\
\text { meters }\end{array}$ \\
\hline Drinking water sources & 10 & 8.5 & 7 & 5 \\
\hline The common water & 4 & 2 & 1 & 0 \\
\hline Protected areas & 7 & 4 & 2 & 0 \\
\hline Hospitals & 5 & 3 & 1 & 0 \\
\hline Schools & 5 & 3 & 1 & 0 \\
\hline
\end{tabular}

\section{Summary}

Through investigation and analysis of different enterprises get the weight value of each factor. Then take the factors: the types of industries (L), the enterprise production scale (A), emergency preparedness and protective measures $(\mathrm{K})$, the distance between enterprises and environmental protection targets $(G)$ into the value of enterprise environmental risk $(R)$, so the larger the value gets, the higher the risk is. Compared with the methods of only considering environmental risk coming from work processes of enterprises, this method is more practical and more accurate [9].

\section{References}

[1]. Keji Wei, Yonghui Song, Jianfeng Peng. Environmental Risk Source and Its Classification. Journal of Safety and Environment. Vol. 10 (2010) No. 1, p. 85-89. 
[2]. Weiliang Wang, Fang Zhang.Study on Environmental Risk Assessment of Sudden Pollution Accident. Resource Development \& Market. Vol. 26 (2010) No. 7, p. 609-616.

[3]. Erbang Hu. Practical Techniques and Methods of Environmental Risk Assessment. China Environmental Science Press, 2000, p. 198-203.

[4]. Xiaosong Yang.Procedures and Methods for Comprehensive Assessment of Regional Environment Risk. Metallic Ore Dressing Abroad. Vol. 11 (1998) No. 1, p. 26-28.

[5]. Yongsen Lu. Environmental Assessment. Tongji University Press, 1999, p. 531-558.

[6]. Zheng Zhang, Yannian Li. Case Analysis of Environmental Risk Assessment of Petrochemical Projects. Environmental Science Research. Vol. 12 (1999) No. 2, p. 32-36.

[7]. Guangming Zeng, Li Zhuo. The Model of Water Environmental Risk Assessment and Application. Water Resources and Power. Vol. 15 (1997) No. 4, p. 28-33.

[8]. Aiwu Liu. Case Study on Environmental Risk Assessment of Chemical Projects. Journal of Guangxi Normal University. Vol. 22 (2005) No. 1, p. 46-47.

[9]. Guiyou Liu, Linyu Xu. Information Diffusion Method for Regional Environmental Risk Assessment. Journal of Environmental Sciences. Vol. 27 (2007) No. 9, p. 1549-1556. 